\title{
Processes of learning in the recognition of eye-signals*
}

\author{
J. H. ELLGRING \\ M. VON CRANACH** \\ Max-Planck-Institut for Psychiatry, \\ Department of Psychology, München
}

\section{Abstract}

In a learning experiment 10 Ss as receivers judged looking signals of a sender. Providing feedback about the real direction of gaze produced learning in the direction of an improvement of discrimination performance; the improvement was independent of visual acuity of receivers and was not. correlated to extraversion and neuroticism. Performance at the beginning was poorer and learning progress better for fixation points which were further away from the face. Results are discussed with reference to improving accuracy of observers on the variable 'looking behavior', important in studies on nonverbal communication. A pretraining of observers which allows explicit feedback about the real direction of gaze is proposed.

Looking behavior as a means of nonverbal communication is seen as having an important signal function in social interaction, and an increasing number of studies are using it as a variable (Argyle, 1969; von Cranach, 1971; Kendon, 1967, 1971; Vine, 1970a). Looking behavior is mostly registered by observers. The basic problem is determining its exact registration. From the early results of Gibson and Pick (1963) and Cline (1967) it was concluded that it is possible to register accurately 'eye-contact' signals (Duncan, 1969).

From the material in these studies it is evident, however, that constant errors of judgments were made. Subsequent studies using the number of correct discriminations as the criterium for exactness of judgment found that judgments were frequently in error (Krueger and Hueckstedt, 1969; Ellgring, 1970). From this, it

* To Professor Gerd Peters for his 65th birthday.
** We are grateful to Mrs. A. C. Peters for her help in preparing the English version of this paper. 
seems unlikely that the occurrence of an eye-contact can be easily affirmed. Detailed discussions of other factors than direction of gaze, influencing the perception of looking behavior are given by von Cranach (1971) and Vine (1970b). In those experiments, where variation of gaze is the dependent variable, other factors such as position of the head and distance being largely held constant, the capacities of the human visual system may have been overloaded with the discrimination task.

Another consideration is that, in daily interactions, the entire context in which the looking behavior takes place contains cues which facilitate more exact decisions about the presence or absence of eye-contact. It is reasonable to believe that the direction of gaze, though important, is only part of the information for judgment of eye-contact. Despite difficulties in the recording of looking behavior and the substantial error-variance that must be taken into account, this variable should not be excluded from studies of nonverbal communication. The problem is to somehow minimize the error component. It is possible to obtain better agreement amongst raters by using a short training period (Argyle and Dean, 1965). However, this agreement does not necessarily mean a more valid rating; high reliability can be achieved by a group of observers building up a particular rating strategy, even though there may be no improvement in validity, as was shown for perception of looking behavior by Stephenson and Rutter (1970).

If the looking behavior of the sender is controlled, that is, if it is known which points are fixated by the sender, it is possible to give explicit feedback about the correctness of judgment to the receiver or observer of looking signals. In earlier studies of perception of looking behavior, feedback to subjects was not considered.

Under different conditions of distance between sender and receiver of looking signals, no increase of discrimination performance was found during experimental sessions without explicit feedback. There are substantial individual differences with respect to discrimination performance which cannot be attributed to variations in acuity or to such personality variables as extraversion and neuroticism (Krueger and Hueckstedt, 1969; Ellgring, 1970). These differences might depend on different individual learning histories. It follows that discrimination performance might improve with explicit feedback. The same assumption of differential learning backgrounds leads to the expectation that, under the condition of a controlled learning situation, the variation of discrimination performance decreases. This decrease of variation has been seen in traditional learning experiments. If learning is a factor, it might be possible to improve accuracy of observation by training. This problem is of theoretical relevance too since the question of the influence of learning processes on specific social signals is involved.

In everyday social situations, where eye-contact may influence the ongoing 
process of interaction, the receiver seldom gets explicit feedback about whether the signal perceived as eye-contact was intended for him or not. But we can assume that perception of looking behavior, like that of other social signals, is partly learned and that the learning processes are basically implicit.

The following hypothesis is taken as a basis for this experiment: By means of explicit feedback, discrimination of looking signals can be improved. In addition, we assume that variation of discrimination performance decreases as a function of training.

\section{Experiment}

Sender (Se) and receiver (R) of looking signals sat opposite at a distance of $300 \mathrm{~cm}$. This distance was considered appropriate for our purpose: according to the results for different distances reported in von Cranach and Ellgring (1971), discrimination performance at this distance is so poor that a 'ceiling effect' is unlikely in the initial part of the experiment. Head-rests guaranteed that head position was as stable as possible for Se and $R$. The experimenter (E) sat behind a screen and was not visible to the $R$. Before each fixation Se was instructed by $E$ via ear phones as to which point to fixate within or beyond R's face. Sound absorbers were necessary to exclude the perception of these instructions from $\mathbf{R}$. The louder acoustic signals such as instructions and buzzer could still be heard (Fig. 1).

Fig. 1. Experimental condition (Explanation in the text)

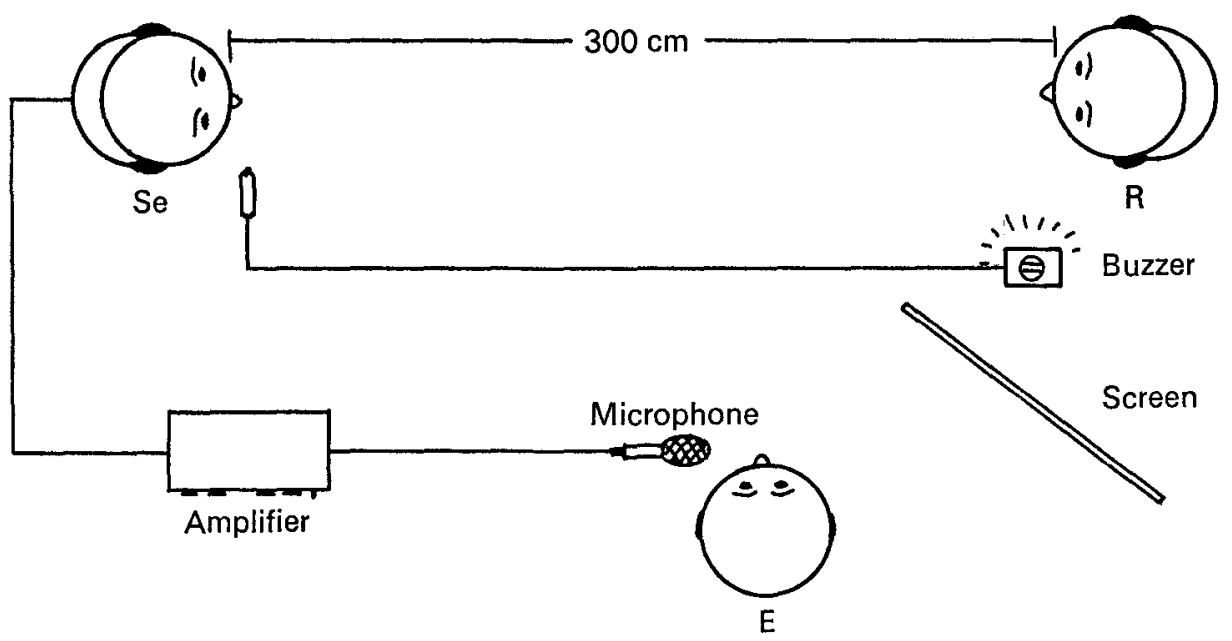


10 students, 7 males and 3 females, age ranging from 20 to 25 years with a mean of 22 figured as receivers of looking signals. One female sender of 23 years was used throughout the experiment. She was trained to look at requested fixation points immediately without substantial search movements. There was no control group since earlier studies with similar population and conditions but without feedback showed no substantial gain in discrimination performance (Krueger and Hueckstedt, 1969, Ellgring, 1970; von Cranach, Hueckstedt, Schmid and Vogel in several unpublished experiments).

Beyond R's face, four fixation points were marked; a further fixation point was designated within R's face, on the bridge of the nose. All fixation points were $20 \mathrm{~cm}$ apart on the eye axis (Fig. 2).

Fig. 2. Fixation points

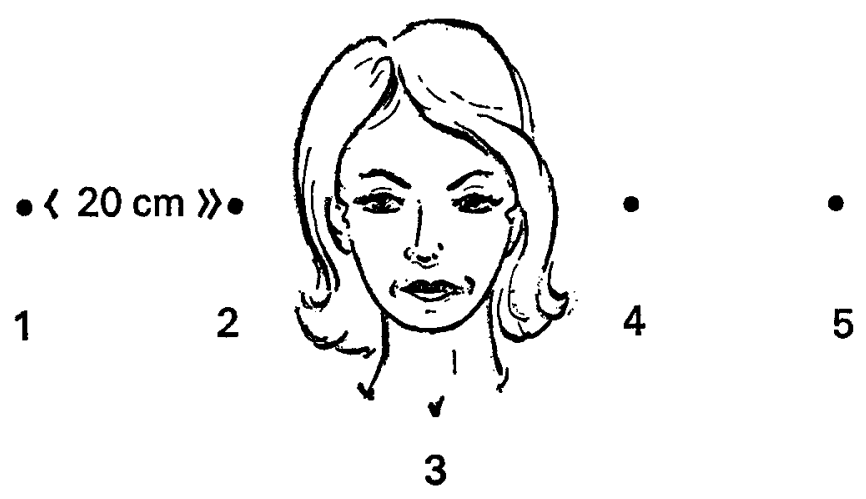

A ledge with five numbered lights was attached above Se's head; the lights corresponded to the fixation points marked on R's eye axis.

The different requests for fixations, i.e. looking signals, were composed according to a table of random numbers (Geigy, 1969) in a stimulus list with 500 signals. Minor pauses followed the 90th, 270th, and 450th looking signals and longer pauses followed the 180th and 360th looking signals. In the first major pause, visual acuity was examined by means of 'Oculus', a table with standardized letters. A questionnaire for extraversion and neuroticism (Brengelmann and Brengelmann, 1960) was completed in the second major pause.

Se fixated the different points according to the instructions of the E. Duration of fixations was between $2.5 \mathrm{sec}$. and $3 \mathrm{sec}$. From earlier experiments (Krueger and Hueckstedt, 1969, Ellgring, 1970) this length of time was found to be convenient for Se and sufficiently long for the R. Between each fixation the Se shortly closed the eyes. The Ss was instructed to attempt to maintain a neutral 
expression during the experiment. As soon as the Se fixated the target point, he activated a buzzer. The $R$ then judged which of the points had been fixated by the Se. The Se provided feedback by stating 'right' or 'wrong' and the number of the point fixated (e.g. 'right, point four'), At the same time the Se activated the corresponding light on the ledge above his head to facilitate orientation for the $\mathbf{R}$. To stimulate higher achievement motivation the subject was offered more or less payment according to his success. In fact all subjects received the same payment. The experiment lasted about 45 minutes.

\section{Results}

\section{Analysis of correct responses}

Learning appeared in the direction of better discrimination of looking signals. The performance of all R's was better at the end of the experiment than at the beginning. For further analysis of data, the single responses were gathered up in blocks of 50. The average performance in the first block was $59 \%$ correct discriminations, relative to 50 fixations. The performance in the last block was $\mathbf{7 2} \%$ correct discrimination (Fig. 3). There was a corresponding decrease of variability

Fig. 3. Correct judgments: Relative frequencies (C\%) for different fixation points; $N=10$, Block $=50$ fixations

c\%

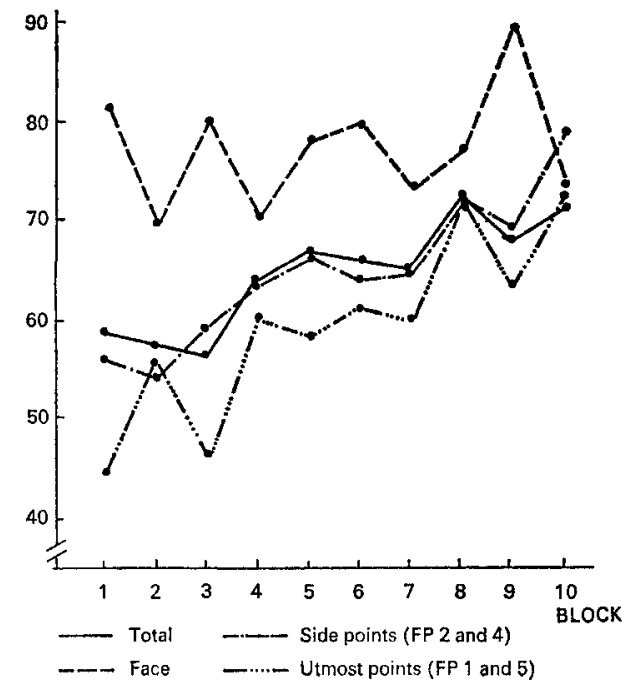


as well (Fig. 4). The correlation between performance in the first block and the last was $T=0.85$ ( $p>0.01 ;$ Kendall's Tau, Lienert, 1962).

Fig. 4. Discrimination performance and its variation in the initial and final part of the experiment: Number of correctly judged looking signals (c) of each $R$ in the 1st and 10th (last) block of 50 fixations; $N=10$

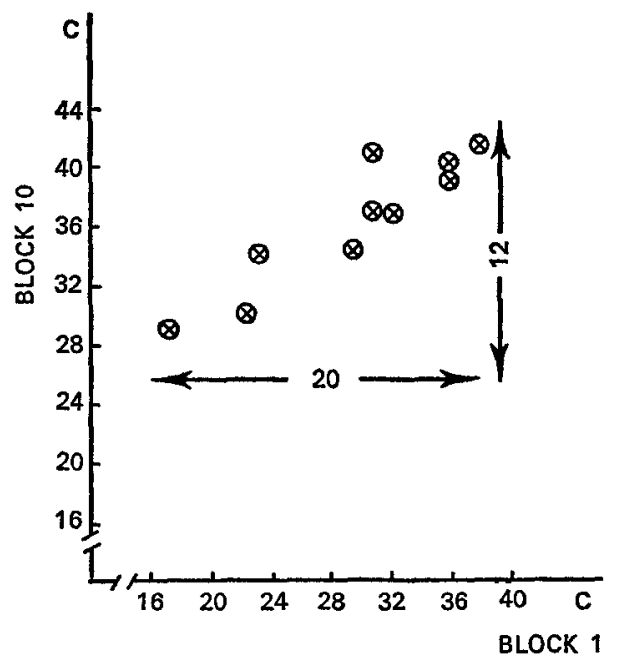

To further analyze the relationship between the learning process and the different target points, the result for the two side target points (2-4) were considered together as were the results for the utmost points (1-5) (Fig. 2). Considering the central target point on the face, in the first block, percentage of correct responses is high ( $82 \%$ ); with $74 \%$ correct responses in the last block, no effect of learning is evident. Considering the side points 2 and 4, correct discriminations substantially increased, indicating the effect of learning (56\% in the first block and $79 \%$ in the last block). The greatest increase of correct discriminations can be seen for the utmost points (1-5): $45 \%$ correct answers in th efirst block and $74 \%$ in the last. Here the lowest initial performance is also found.

\section{Analysis of errors}

Here, the extent of errors and their direction is examined.

With respect to extent of error, differences between fixated target points and responded points are considered. These differences are valued from 1 to 4 points 
according to the amount of discrepancy (units of $20 \mathrm{~cm}$ ) between the fixated point and the responded point. Errors of four points never occurred, errors of three points only occurred in the initial phase. Errors of 3 points in the first block consisted of $0.5 \%$ of the total number of errors and a maximum of $2.3 \%$ errors was reached in the third of 20 blocks of trials. Incorrect judgments of two points have a quota of $12.1 \%$ of the total amount of error in the first block. This percentage decreases to $2.2 \%$ in the last block. In Fig. 5 relative frequencies of total error and incorrect judgments of one and two points are presented. Incorrect judgments of three points do not appear in the scale used here. A decrease of curves and an approach of the curve for total error with the curve for incorrect judgments of one point, can be seen.

Fig. 5. Relative frequencies of incorrect judgments ( $\mathrm{J} \%$ ); $N=10$, Block $=50$ fixations

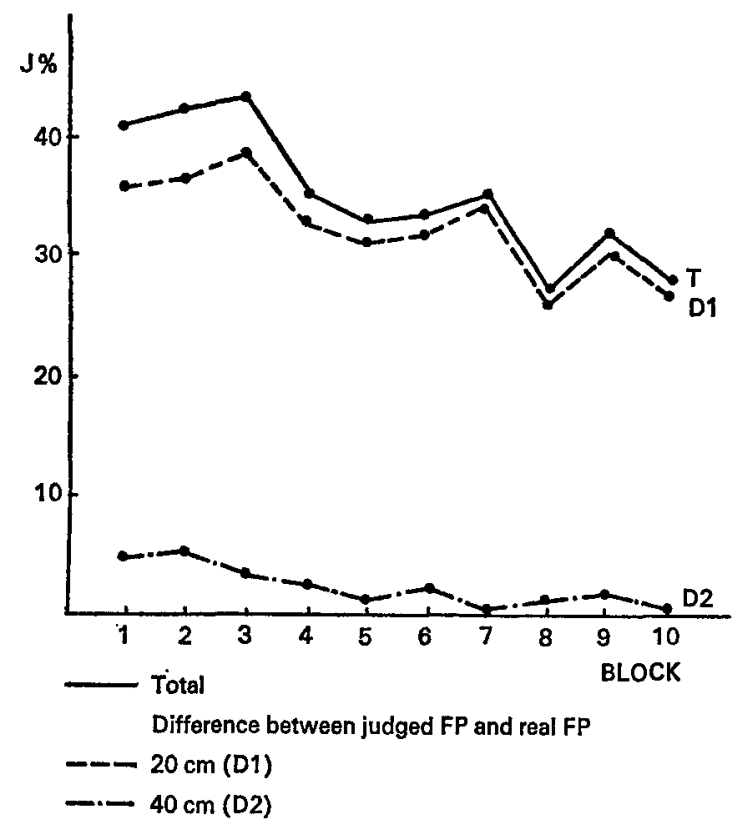

For purpose of qualitative analysis of errors, that is the direction of errors, only the two side target points 2 and 4 could be considered (Fig. 2): Only with these points it was possible for $\mathbf{R}$ to respond incorrectly in the direction of the central point (face) or in the direction of the utmost points (1 and 5). Here a slightly increasing amount of error in the direction of the utmost points can be seen. With 
errors in direction of the central point (face), the initial frequency is substantially higher and continuously decreases. With respect to this tendency there is no significant difference between points 2 and 4 , and consequently they are shown together.

Fig. 6. Direction of incorrect judgment for side points (FP 2 and 4): Relative frequencies of incorrect judgments $(\mathrm{J} \%)$ in direction of utmost fixation points (FP 1 and 5) and in direction of the central point (face, FP 3); $N=10$, Block $=50$ fixations

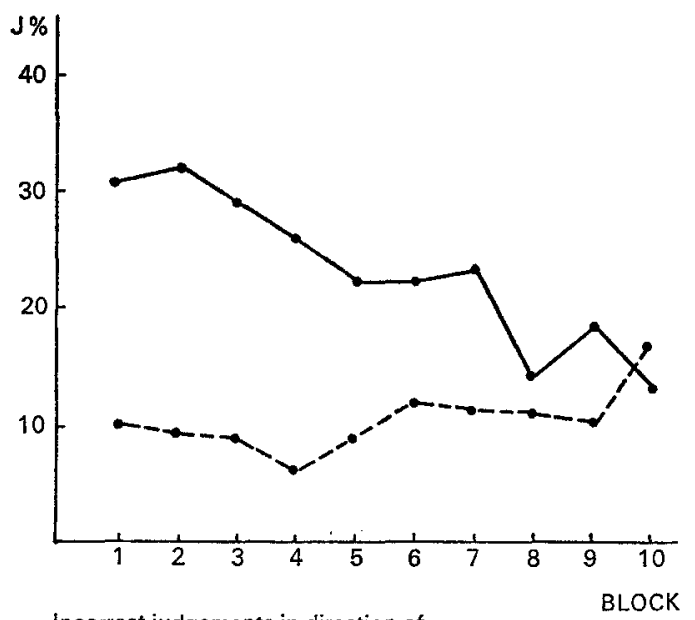

Incorrect judgements in direction of - Face (FP 3)

- - - Utmost points (FP 1 and 5)

Fig. 6 shows the relative frequencies of fixations of the side target points, which are judged as fixations of the utmost points, and those which are judged as fixations of the central point. In the later blocks it can be seen that both types of errors occurred equally often.

\section{Correlations with external variables}

To determine the correlative relationships between external criteria and rate of learning the difference between frequency of correct discriminations in the first and the last block of 50 trials is taken as measure of rate of learning. Visus ranged from 60 to 100 with a mean of 86 , where 120 would be the highest value. Extraversion ranges from 5 to 14 with a mean of 8,7 , neuroticism from 8 to 19 with a mean of 11.3. The correlation between the defined rate of learning and visual acuity is statistically insignificant $(\mathrm{T}=0.32, \mathrm{p}>0.10)$. Correlations with extraversion $(\mathrm{T}=0.09, \mathrm{p}>0.10)$ and neuroticism $(\mathrm{T}=0.26, \mathrm{p}>0.10)$ are insignificant as well. 


\section{Discussion}

The present experiment shows that by means of explicit feedback it is possible to reach a more exact discrimination of looking signals. The improvement of discrimination performance does not correlate with the personality variables extraversion and neuroticism and is almost independent of visual acuity of subjects.

The decreasing variation in discrimination performance and the asymptotic shape of the learning curve indicate that in this experiment the last part of a theoretically longer learning curve was produced. The characteristics of the learning curve support the assumption that the subjects have different learning histories. These differences in learning histories, however, are balanced by the experimental conditions set, and thus loose their importance. From the high correlation between performance in the first block and the last, it follows, however, that constant individual differences with respect to discrimination of looking signals were present, which cannot be accounted for by the personality variables extraversion and neuroticism. Visual acuity seems to be an unrelated variable too. Perhaps motivational factors could play a role here. In assessing the correlations, however, the small number of subjects and the small range of values must be considered.

Important for the conclusions that can be drawn from the experiment are the poor performance in discrimination and the better success of learning for points that are further from the face. The distance of target points from the face is related to a difficulty dimension, indicated by poorer discrimination performance for the outer target points. The position of the receiver with respect to the utmost fixation points can be compared with that of an observer directly behind the receiver. Therefore it cannot be expected that such observers of looking signals show a better discrimination performance than did the receivers in this study with respect to the utmost points. For studies in which looking signals are considered as a variable of communicative behavior, this means that validity of observations must be critically examined and substantial noise factors considered.

Our experiment demonstrates that after a relatively short period of training a substantial improvement of discrimination performance can be reached. To our knowledge there are no studies in which observers were trained before the onset of the real experiment using explicit feedback concerning the correctness of their judgments.

It is of course impossible to provide feedback about the actual direction of gaze when the behavior of the sender cannot be controlled. This is the case with field studies of natural conversation. In investigations of these situations it would be 
useful and even necessary to somehow pre-train observes by using explicit feedback about the real looking behavior.

The constant individual differences with respect to discrimination performance can be understood within the frame of reference of Argyle's (1969) 'social skill' model. One aspect could be the perception of looking signals. In observation studies, observers would be selected according to their skill in the discrimination of looking signals. At least the content validity of the variable 'looking behavior' would be improved through selection of observers and their training.

\section{REFERENCES}

Argyle, M. (1969) Social Interaction. London, Methuen.

Argyle, M., and Dean, J. (1965) Eye-contact, distance and affiliation. Sociometry 28, 289-304.

Brengelmann, J. C., and Brengelmann, L. (1960) Deutsche Validierung von Fragebogen der Extraversion, neurotischen Tendenz und Rigidität. Z. exp. angew. Psychol. 7, 291-331.

Cline, M. (1967) The perception of where a person is looking. Amer. J. Psychol. 80, 41-50.

Von Cranach, M. (1971) The role of orienting behavior in human communication. In: Esser, A. H. (Ed.) Behavior and environment: The use of space by animals and men. New York, Plenum Press, 217-237.

Von Cranach M., and Ellgring, J. H. (1972) The perception of looking behavior. In: Von Cranach, M., and Vine, I. (Eds) Body movement and non-verbal communication. London, Academic Press, in preparation.

Duncan, S. (1969) Nonverbal communication. Psychol. B. 72, 118-137.

Ellgring, J. H. (1970) Die Beurteilung des Blickes auf Punkte innerhalb des Gesichtes. Z. exp. angew. Psychol. 17, 600-607.

Geigy (1968) (Hg) Documenta Geigy: Wis- senschaftliche Tabellen. Basel, Geigy. Gibson, J. J., and Pick, A. D. (1963) Perception of another person's looking behavior. Amer. J. Psychol. 76, 386394.

Kendon, A. (1967) Some functions of gaze direction in social interaction. Acta psychol. 26, 22-63.

Kendon, A. (1971) The role of visible behaviour in the organization of social interaction. In: Von Cranach, M., and Vine, I. (Eds) Body movement and nonverbal communication. London, Academic Press, in preparation.

Krueger, K., and Hueckstedt, B. (1969) Die Beurteilung von Blickrichtungen. $Z$. exp. angew. Psychol. 16, 452-472.

Lienert, A. (1962) Verteilungsfreie Methoden in der Biostatistik, Meisenheim, Hain.

Stephenson, G. M., and Rutter, R. (1970) Eye-contact, distance and affiliation, a re-evaluation. Brit. J. Psychol. 61, 385393.

Vine, I. (1970a) Communication by facialvisual signals. In: Crook, J. H. (Ed.) Social behavior in birds and mammals. London, Academic Press, 279. 353.

Vine, I. (1970b) Judgment of direction of gaze - An interpretation of some discrepant results. University of Bristol, unpublished paper. 


\section{Résumé}

$\mathrm{Au}$ cours d'une expérience sur l'apprentissage, 10 sujets se comportant comme des récepteurs ont jugé les signaux du regard d'un envoyeur. En fournissant de la rétroaction quant à la vraie direction du regard on a obtenu un apprentissage dans le sens d'une amélioration de la performance discriminatoire: l'amélioration était indépendante de l'acuité visuelle des récepteurs et n'était pas corrélative à l'extraversion ou au caractère névrosé des sujets. Au début la performance était plus médiocre et le progrès dans l'apprentissage meilleur dans le cas des points de fixation qui étaient les plus éloignés du visage. On discute des résultats en vue d'améliorer la précision des observateurs sur la variable "comportement du regard' important dans les études sur la communication nonverbale. On propose un entraînement préalable des observateurs, entraînement qui permet une rétroaction explicite quant à la vraie direction du regard.

\section{Zusammenfassung}

In einem Lernexperiment beurteilten 10 Vpn als Empfänger die Blicksignale einer Person, die als Sender fungierte. Die Diskriminierungsleistung der Empfänger verbesserte sich als Folge von feedback-Informationen. Die verbesserte Leistung war unabhängig von der Sehschärfe und korrelierte nicht mit Extraversion und Neurotizismus. Für Zielpunkte des Blicks, die weiter vom Gesicht entfernt waren, war die Leistung am Anfang schlechter und die Leistungsverbesserung ausgeprägter. Die Ergebnisse werden im Hinblick auf eine größere Genauigkeit bei der Beobachtung der Variablen 'Blick-Verhalten' diskutiert, was für Untersuchungen über non-verbales Verhalten wichtig ist. Für Beobachter werden Trainings-Programme vorgeschlagen, bei denen Rückmeldungen über die tatsächliche Blickrichtung des Senders vermittelt werden können. 